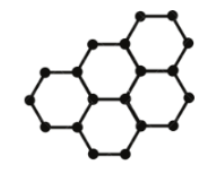

ICONSMAT Institute of
Costruction Materials
Content list available at ICONSMAT

Journal of Construction Materials

Journal homepage: www.iconsmat.com.au/publication
Article history:

Received 2 December 2021

Received in revised form

6 December 2021

Accepted 29 December 2021

Available online 29 December 2021

\title{
Recycling behaviour in a multicultural urban area in Sweden
}

\author{
Krushna Mahapatra ${ }^{1}$, Atefeh Dadvar ${ }^{1 *}$, Brijesh Mainali $^{1}$ \\ ${ }^{1}$ Linnaeus University, Faculty of Technology, Department of Built Environment and Energy Technology. \\ *Corresponding author: PhD candidate, E: atefeh.dadvar@|nu.se
}

\begin{abstract}
Alabastern, a multicultural rental housing area in the Växjö city of Sweden, was identified as poor at recycling household waste compared to other housing areas in the town. In this paper, a qualitative and quantitative analysis is conducted to understand the underlying causes of waste recycling behaviour of the tenants. Results showed that majority of the studied participants perceived themselves to be environmentally friendly. They reported that they recycled household waste quite often, but it was the other tenants who did not sort their waste properly. The respondents identified the causes of the improper waste recycling as lack of attitude and awareness, limitation of communication, sense of insecurity, lack of means to transport bulky waste, limitation of the recycling room, and inadequate action by the housing company Växjöbostäder.
\end{abstract}

DOI: 10.36756/JCM.v3.1.4 C2021 Institute of Construction Materials

\section{Keywords}

Household behavior, multicultural, waste management, waste recycling. 


\section{Introduction}

Waste management has been widely recognized as a global concern due to its great impacts on health, environment and economy [1]. It is forecasted that the waste quantity in Sweden will be doubled by 2030 if no attempt is made to change the trend [2]. Hence, in 2003, the Swedish Government instructed the Environmental Protection Agency (EPA) to prepare a national waste plan [3], in which prevention is given the most priority followed by reuse, recycling, biological treatment and disposal.

Recycling is known as one of the most crucial actions available to decrease the environmental impact of waste [2]. Waste recycling systems in residential segment mainly depend on consumers' or end users' engagement and behaviour [4]. A large number of studies have investigated the factors that may influence household behaviour of waste recycling [5]-[10]. Environmental behaviour of households including recycling is known to be complex and varied [11]. A number of studies revealed that the predictors of recycling behaviour comprise a large set of variables [12]-[14]. Thomas and Sharp [15] categorized recyclers and non-recyclers by presenting a list of factors that have an impact on the decision to recycle. Such factors include social-demographic, economic status, awareness, environmental attitudes, beliefs and value, the influence of family and friends, social norms, access to facilities and services that enables participation in recycling. Belton et al. [16] concluded that the three main reasons for households not using recycling centers in Glasgow were the perception that the centers were too far away, apathy, and a lack of interest in recycling. In contrast, Perrin and Barton [17] identified environmental concerns as the most important reason for participation, with convenience being the second important reason. They also concluded that more mature, affluent, and educated homeowners have higher tendency to be recyclers. Furthermore, Belton et al. [16] documented that non-recyclers are more likely to be younger people in lower socio-economic groups. Vencatasawmy et al. [18] stated that the recyclers at a small town in northern Sweden are more likely to be married, without children, retired, more affluent, owner-occupiers, higher educated and concerned for the environment. Meneses and Palacio [6] identified that women recycle more than men. Other studies have concluded that residents of single-family dwellings recycle more than multifamily dwellings $[19,20]$.

Barr et al. [21] theorize that recycling behaviour is dependent on three groups of factors: environmental values, situational variables and psychological variables. Martin et al. [22] list situational and psychological factors as more significant factors in determining individuals' recycling behaviour. Existing literature investigated the role of a wide range of psychological factors (e.g., attitudes, beliefs and values; social influences and social and personal norms, identity, perceived control and self-efficacy) in recycling behaviour [22-25].

Even though considerable amount of research has focused on recycling behaviour; there is, however, limited number of studies on the recycling behaviour of residents in multicultural urban areas [26]. In today's world, migration and urbanization are characteristics of the globalization process and multicultural residential districts are increasingly visible in urban areas. Understanding of multicultural attitudes and behavioural algorithm is essential to increase the recycling rate [11].

Hage et al. [27] reported that when immigrants arrive in a new place, they are not familiar with laws and regulations, and their language proficiency might not be high enough, which can result in low participation rates in recycling. However, they [27] concluded that, after a period, immigrants adopt existing social norms of behaviour and recycle even more than the average native citizens. In contrast, Resource Recovery Forum (RRF) pointed out that ethnic minorities recycle less [28]. Perry and Williams [26] studied recycling behaviour of a multicultural area in Preston, Lancashire. They found that different ethnic groups have different waste management behaviour. For instance, British Indians are more likely to participate in recycling than their white British counterparts. In addition, they pointed out that the 
third generation of ethnic minorities tend to have greater concern and awareness about environmental issues while they reuse less compared to their parents and grandparents [26].

Martin et al. [22] identified that second generation immigrants had a much lower tendency to recycle compared to their parents. In a study among Järva households in Stockholm, Sweden, Miafodzyeva, el al. [11] concluded that attitude toward the importance of recycling was the main factor in recycling behaviour. Environmental concern, satisfaction with the facilities provided, recycling confidence, community identity and socio-demographical factors did not have significant impact on their recycling behaviour. However, generalization of the results from these limited number of studies require more studies of multicultural householders in different geographical areas. This paper compliments existing studies and analyzes the influence of different physical, social and psychological factors on waste recycling behaviour in the Alabastern residential area in the Växjö city of Sweden. In particular, this paper examines whether variables such as awareness about environmental problems, attitude towards environment, gender, education, and time lived in Sweden influence participation in recycling behaviour. Additionally, obstacles to recycling in the studied area are investigated and suggestions for improving the recycling behaviour is discussed.

Although improving recycling behaviour is undoubtedly one of the most effective methods in a given waste management strategic plan, the emergence of new technologies equipped with Al, image processing programs and Neural Network programming features can enhance the status quo of the waste recycling in a much better effective way [32-38].

\section{The study area and household waste problem}

Växjö is a medium size town (ca 100000 inhabitants) located in the south of Sweden. This city is well known for environmentally-friendly actions such as renewable-based public transportation, timberframe multi-storey buildings, and biomass-based combined heat and electricity production system. Majority of the residents sort different fractions of household waste, e.g. plastic, glass, paper, cardboard, metal, food waste and rest material. However, there seems to be variation in level of waste recycling among different housing districts in the town. The municipality-owned housing company Växjöbostäder, which owns the large majority of rental housing in Växjö, experienced that the Alabastern area in the Araby housing district, which is dominated by immigrants from Africa and Middle-eastern countries, was not good at recycling household waste compared to other housing areas in the town. Tenants did not sort household waste as per waste separation guidelines. Large size waste such as mattress and furniture were left outside of the buildings, unsorted waste was found both inside and outside the recycling rooms, and cans and bottles could be found on grass lawns. Växjöbosäder reported that the cost of waste management and cleaning in the Alabastern area was considerably higher than that of other housing areas [31].

\section{Method}

\section{A. Questionnaires}

A self-completion questionnaire was distributed to 313 apartments in the studied area. To overcome the language and cultural barriers to reach the tenants, four individuals (three females and one male) from the locality were hired and trained to work in the project. They knocked the door of each apartment and delivered the questionnaire to those who opened, and explained the waste recycling guide to those willing to talk. A large majority did not open the door and therefore, the questionnaire 
and a prepaid return envelope was left in the post box. This resulted in 63 individuals responding to the survey, but all participants did not respond to all questions. Hence, we report the number of observations ( $n$ ) for each analyzed question. The composition of the participants is reported in Table 1.

Table 1-Description of the socio-demographic characteristics of respondents

\begin{tabular}{llc}
\hline \hline & Variable & Alabastern \\
\hline \multirow{3}{*}{ Gender (N=54) } & Man & $52 \%$ \\
& Woman & $46 \%$ \\
& Other & $2 \%$ \\
\hline \multirow{3}{*}{ National origin (N=54) } & Swedish & $37 \%$ \\
& Somalia & $17 \%$ \\
& Arabic (Iraq, Syria, Yemen) & $33 \%$ \\
& Others & $13 \%$ \\
\hline Years living in Sweden (N=34) & $1-5$ years & $12 \%$ \\
& $5-10$ years & $18 \%$ \\
& $>10$ years & $71 \%$ \\
\hline \hline
\end{tabular}

Information collected in this questionnaire included:

1. Respondents' participation in recycling behaviour for eight types of waste (glass, metal, paper packages, newspapers, plastic, food/bio waste, lamps/batteries/electronics, furniture and carpets).

2. Respondents' awareness about environmental issues.

3. Respondents' attitude towards environment.

4. Respondent's socio-economic characteristics, including: gender, education, and years living in Sweden.

5. Difficulties in sorting household waste.

\section{B. Interviews}

Two focus group interviews were conducted to access the views of tenants of Alabastern area. The para-professional aids led the discussions in multiple languages (Somalian, Arabic, and Swedish) and the interviews were electronically recorded with the permission of the participants.

\section{Results}

Fig. 1 shows that around $80 \%$ of the respondents stated that they frequently separate all fractions of their waste. Around $7 \%$ to $10 \%$ never separated at least one fraction of the waste. More respondents sorted paper or furniture than plastic or metal. 


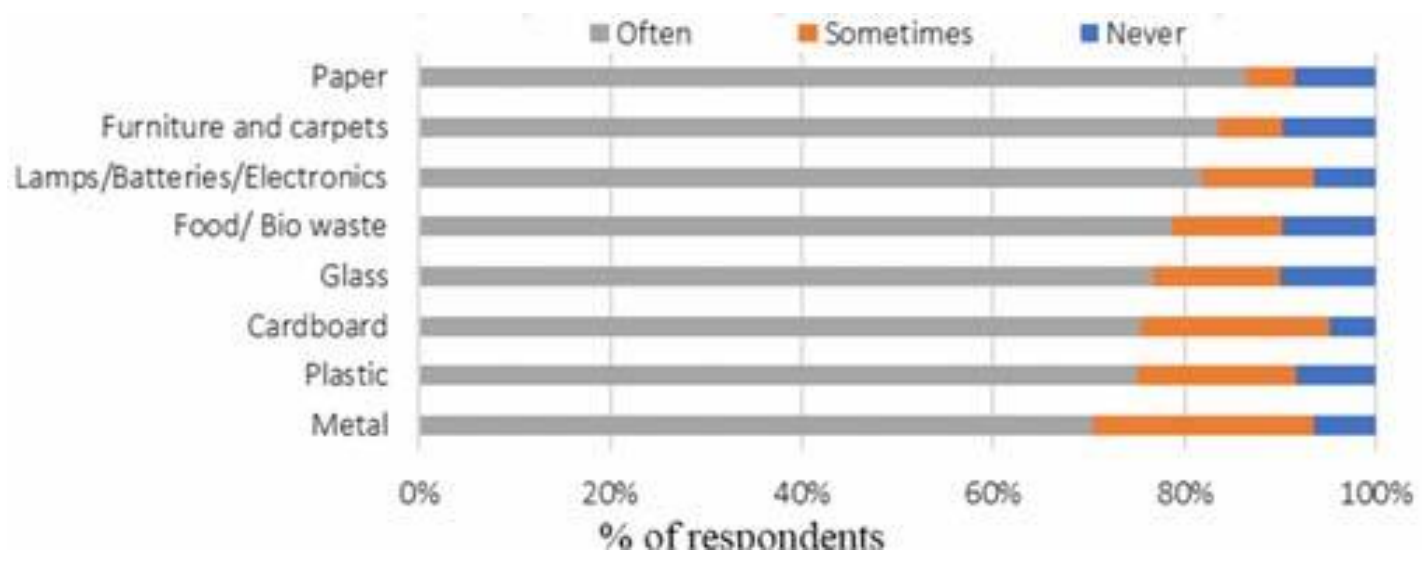

Figure 1-How often the respondents recycled their households?

\section{A. Awareness and attitude towards environment}

Most of participants mentioned that they were aware of environmental issues and the causes of environmental problems, but a smaller proportion knew about solutions to those problems (Fig. 2). Around $55 \%$ of the respondents stated that, in comparison with others, they are doing enough or more than enough towards the environment.

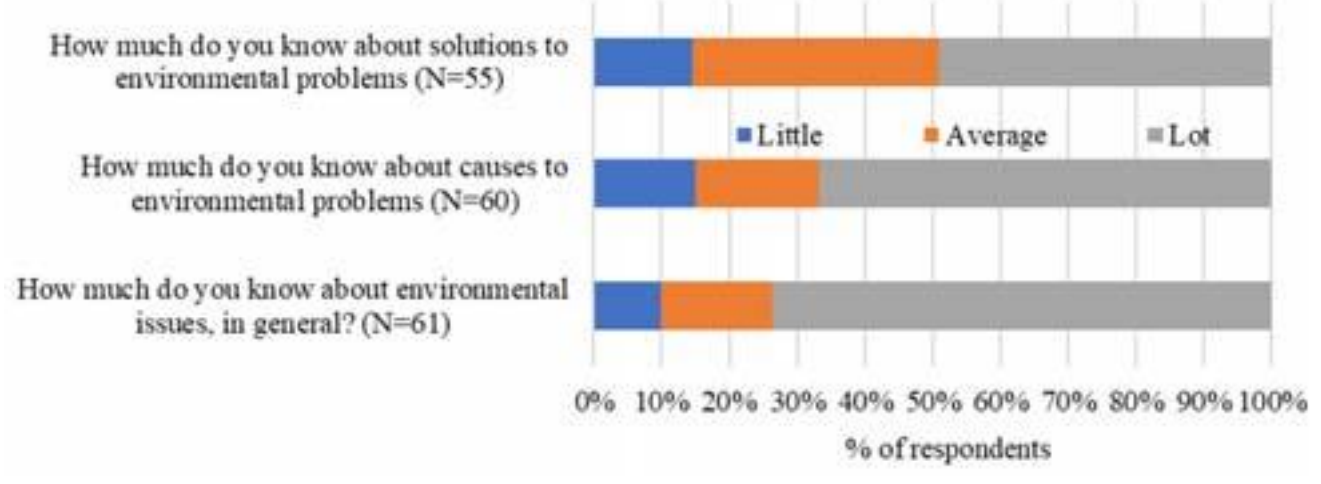

Figure 2-Awareness about the environmental issues

The questionnaire survey included a number of statements about attitude towards environment. Respondents could respond to the statements in a 5-point Likert scale ( $1=$ do not agree at all, $5=$ completely agree). The responses were restructured by combining points 1 and 2 to one category (disagree) and points 4 and 5 to third category (Agree). Results reported in Fig. 3 show that about $70 \%$ of respondents agreed that they engaged in activities that are best for the environment even though it costs money and time. In contrast, about $30 \%$ had a negative attitude as they thought that many environmental statements are exaggerated, they were not willing to pay higher taxes to protect the environment, or felt that environmental protection is wasteful if no one else is doing it. 
I do the things that is the best for the environment. even if it cost time and money $(\mathrm{N}=62)$

Almost every thing we do in the modern society destroys the environment $(\mathrm{N}=61)$

It's difficult for an individual to protect the environment $(\mathrm{N}=62)$

We are worry ing too much about the environment and too little about the econouny and jobs $(\mathrm{N}=62)$

Environmental problems have a direct effect on my daily life $(\mathrm{N}=63)$

Many statements about the environmental threat are excessive $(\mathrm{N}=62)$

I am willing to pay higher taxes to protect the environment $(\mathrm{N}=62)$

There is no point for me to protect the environment if nobody else is doing it $(\mathrm{N}=63)$

I think it is difficult to know if my lifestyle is environmental friendly or not $(\mathrm{N}=63)$

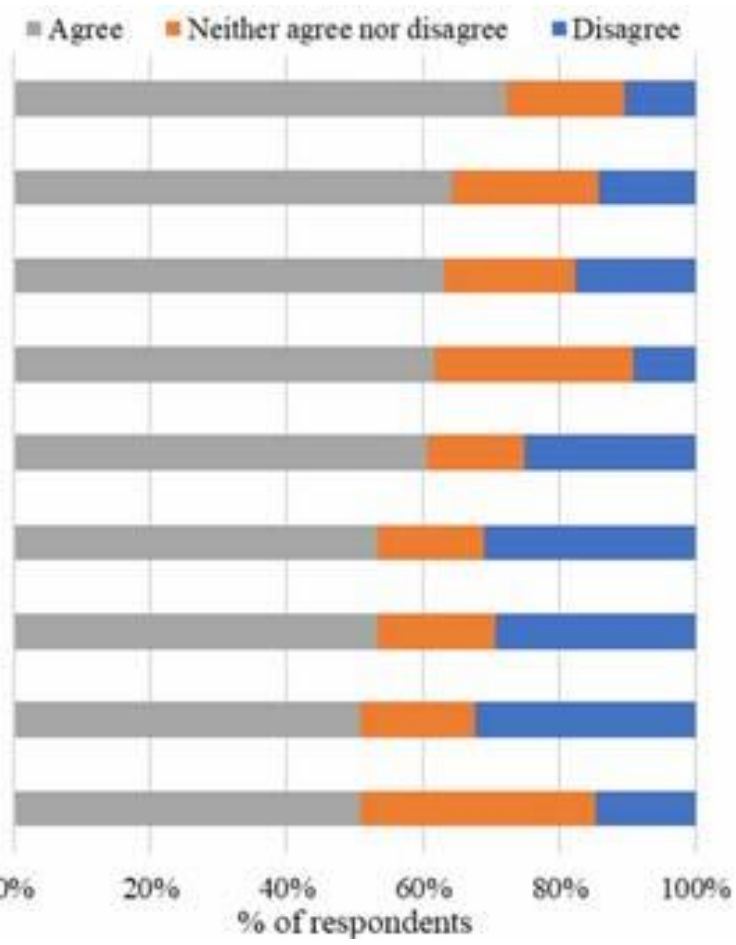

Figure 3-Attitude toward the environment

\section{B. Difficulties in waste recycling}

Fig. 4 shows that most of the respondents believed that "others", e.g., people in surrounding area, and insufficient action by Växjöbostäder, cause the waste recycling problem in Alabastern area. However, around $20-25 \%$ of the respondents blamed themselves, e.g., lack of time or interest to recycle. Around $50 \%$ mentioned unavailability of vehicle or driving license as an issue, while $40 \%$ reported shortage of space in the apartment as a limitation.

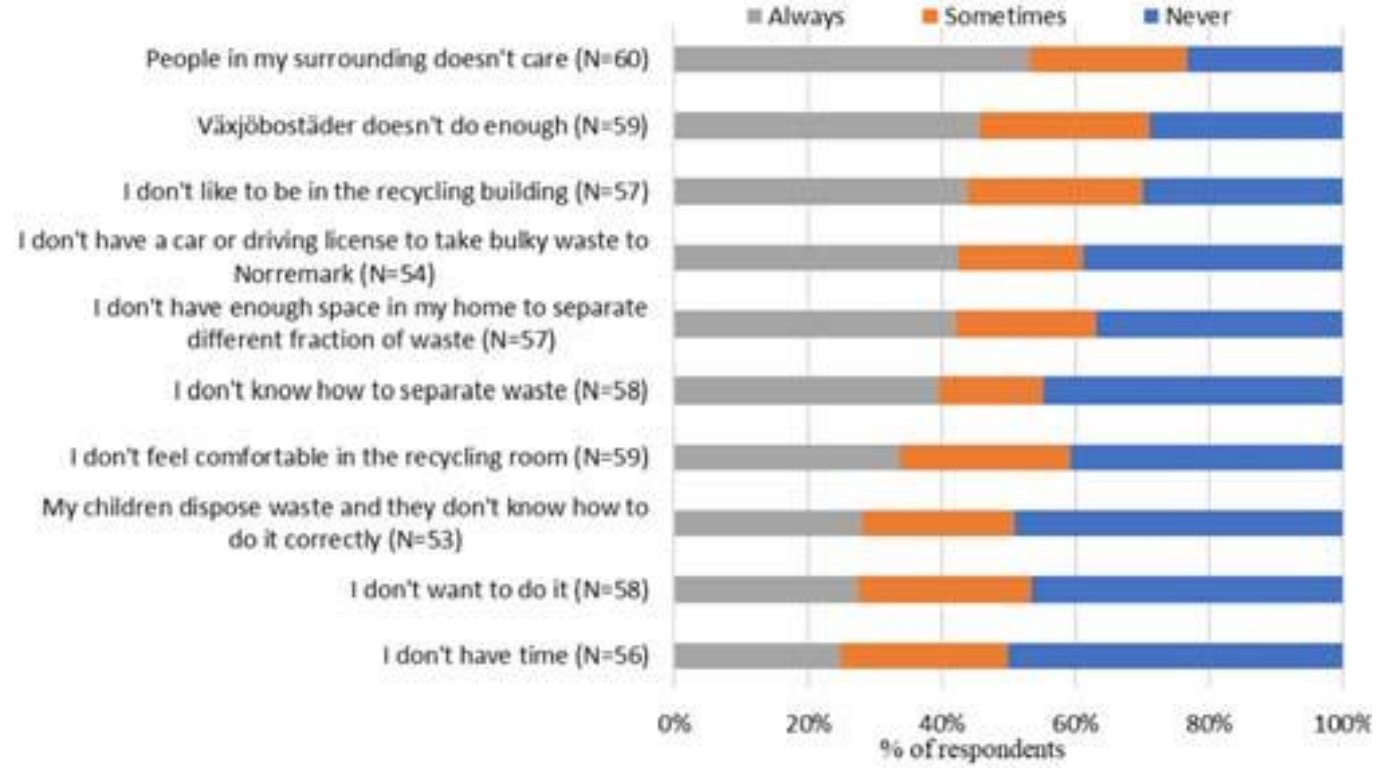

Figure 4-How often the respondents experienced different factors while disposing household waste? 


\section{Correlation analysis}

For better understanding of impacts of social and psychological factors on people's recycling behaviour, correlation analysis is known to be helpful [11]. Spearman's correlation analysis between respondents' awareness about environmental problems, attitude towards environment, gender, education and time lived in Sweden (independent variables), and behaviour variables (dependent variables) i.e., the reported frequency at which different fractions of household waste was recycled, demonstrated insignificant correlation coefficients. Hence, it could not be concluded that the considered variables have any impact on recycling behaviour of tenants (see Table II). These results are in agreement with similar studies [11].

Table 2-Spearman correlation coefficients

\begin{tabular}{cccccc}
\hline \hline & $\begin{array}{c}\text { Awareness } \\
\text { about } \\
\text { environmental } \\
\text { issues }\end{array}$ & $\begin{array}{c}\text { Attitude } \\
\text { toward } \\
\text { environment }\end{array}$ & Gender & Education & $\begin{array}{c}\text { Time } \\
\text { living in } \\
\text { Sweden }\end{array}$ \\
\hline Glass & 0.059 & -0.085 & 0.048 & -0.11 & -0.045 \\
Metal & 0.079 & -0.049 & 0.006 & -0.06 & 0.011 \\
Paper packages & 0.045 & 0.036 & 0.03 & -0.05 & -0.017 \\
Newspapers & -0.027 & -0.093 & 0.196 & -0.09 & -0.163 \\
Plastic & -0.007 & -0.02 & 0.038 & -0.16 & -0.054 \\
Food/bio waste & 0.05 & 0.065 & -0.026 & 0.01 & -0.103 \\
Lamps/Batteries/Electronics & 0.048 & -0.274 & 0.081 & 0.14 & -0.029 \\
Furniture and carpets & 0.292 & -0.081 & 0.098 & 0.03 & -0.155 \\
\hline \hline
\end{tabular}

There was a very small correlation between recycling behaviours (for eight different waste fractions) and awareness about environmental issues or attitude toward the environment. Unexpectedly correlation coefficient for attitude toward the environment and recycling of glass, metal, newspapers, plastic, lamps/batteries, furniture and carpet is negative. Correlation coefficient between awareness about environmental issues and recycling of newspapers and plastic is also negative.

The socio-demographical variables (i.e., gender, education, and time living in Sweden) were also weakly correlated with the recycling behaviours regarding the eight waste fractions indicating no determinants of recycling behaviour among these variables. This is in agreement with existing literature that reported no correlation of socio-demographical variables with recycling behaviour [27], [29], [30].

\section{D.Tenants' perception on waste recycling}

The above results were corroborated by the findings from the interviews. The interviewed tenants mentioned that the main reasons for inappropriate waste recycling behaviour include lack of information in their own language, insufficient knowledge about benefits of recycling, negligence, no driving license or vehicle to transport large items to central recycling station of Växjö, sense of insecurity for ladies to go into the recycling room, and bad smell in the recycling due to lack of ventilation. When children were entrusted to through the waste, they threw it outside of the recycling room because they did not have the key to the recycling room or they could not open the heavy door. The interviewed tenants also mentioned that people from adjacent areas loiter in Alabastern and Växjöbostäder does not take adequate responsibility to keep the area clean. 
The interviewed tenants also suggested a number of solutions to the waste recycling problem. Their suggestions included dissemination of multilingual printed material on waste recycling, frequent information gatherings planned by Växjöbostäder, and education of children and adults. They also proposed installation of surveillance cameras in and around recycling rooms, arrangement of containers for large items 2-3 times a year, replacing the heavy doors of the recycling rooms with easy to open doors, installation of windows to improve visibility and security of the recycling room, restructuring recycling room to make it possible to throw garbage in separate bins from outside, and provision of different colour garbage bags for different fractions of waste.

\section{Conclusion}

Alabastern area is dominated by immigrants, mainly from some African and Middle Eastern countries. As multicultural urban areas now make up a considerable proportion of the Swedish society, it is crucial to increase the participation of different ethnic groups of households in waste recycling. It is commonly accepted that recycling targets would not be met without the support of multicultural urban areas [11].

The quantitative and qualitative analysis revealed that even though the self-reported level of awareness about environmental issues and attitude toward the environment was high, recycling behaviour was not significantly correlated to these factors. This study also showed that variables such as age, education, and time lived in Sweden were not determinants of recycling behaviour in the studied area. The tenants participating in our study mentioned that they recycle household waste quite often, but it is the "others" who do not do so.

The participants suggested several informational and technical measures to address the recycling problem in Alabastern area. Results of our study may help the housing companies and local authorities to consider a variety of strategies to improve waste recycling behaviour in multicultural urban areas.

\section{Acknowledgement}

The authors would like to acknowledge funding organization for supporting this research. This research work is partly financed by the Viable Cities program of Swedish Energy Agency (project number 487761) and EC Support from the European Union's Seventh Framework Program for research, technological development and demonstration under grant agreement no. ENER/FP7/609127/READY. 


\section{References}

[1] Saffron, L., L. Giusti, and D. Pheby, The human health impact of waste management practices: A review of the literature and an evaluation of the evidence. Management of Environmental Quality: An International Journal, 2003. 14(2): p. 191-213.

[2] Johansson, K., Understanding recycling behaviour: a study of motivational factors behind waste recycling. WIT Transactions on Ecology and the Environment; WIT Press: Ashurst, UK, 2016. 202: p. 401414.

[3] The Swedish Waste Management Association, Swedish Waste Management. 2018: Malmö, Sweden.

[4] Howenstine, E., Market segmentation for recycling. Environment and Behaviour, 1993. 25(1): p. 86-102.

[5] McDonald, S. and C. Oates, Reasons for non-participation in a kerbside recycling scheme. Resources, conservation and recycling, 2003. 39(4): p. 369-385.

[6] Meneses, G.D. and A.B. Palacio, Recycling behaviour: a multidimensional approach. Environment and behaviour, 2005. 37(6): p. 837-860.

[7] Oke, A., Workplace waste recycling behaviour: A meta-analytical review. Sustainability, 2015. 7(6): p. 7175-7194.

[8] Passafaro, P., S. Livi, and A. Kosic, Local norms and the theory of planned behaviour: Understanding the effects of spatial proximity on recycling intentions and self-reported behaviour. Frontiers in psychology, 2019. 10: p. 744.

[9] Refsgaard, K. and K. Magnussen, Household behaviour and attitudes with respect to recycling food waste-experiences from focus groups. Journal of Environmental management, 2009. 90(2): p. 760-771.

[10] Steg, L. and C. Vlek, Encouraging pro-environmental behaviour: An integrative review and research agenda. Journal of environmental psychology, 2009. 29(3): p. 309-317.

[11] Miafodzyeva, S., N. Brandt, and M. Andersson, Recycling behaviour of householders living in multicultural urban area: a case study of Järva, Stockholm, Sweden. Waste Management \& Research, 2013. 31(5): p. 447-457.

[12] Coggins, P., Who is the recycler. Journal of Waste Management and Resource Recovery, 1994. 1(2): p. 1-7.

[13] McDonald, S. and R. Ball, Public participation in plastics recycling schemes. Resources, Conservation and Recycling, 1998. 22(3-4): p. 123-141.

[14] Tucker, P., Normative influences in household waste recycling. Journal of Environmental Planning and Management, 1999. 42(1): p. 63.

[15] Thomas, C. and V. Sharp, Understanding the normalisation of recycling behaviour and its implications for other pro-environmental behaviours: A review of social norms and recycling. Resources, Conservation and Recycling, 2013. 79: p. 11-20. 
[16] Belton, V., et al., A survey of public attitudes to recycling in Glasgow (UK). Waste Management \& Research, 1994. 12(4): p. 351-367.

[17] Perrin, D. and J. Barton, Issues associated with transforming household attitudes and opinions into materials recovery: a review of two kerbside recycling schemes. Resources, Conservation and Recycling, 2001. 33(1): p. 61-74.

[18] Vencatasawmy, C.P., M. Öhman, and T. Brännström, A survey of recycling behaviour in households in Kiruna, Sweden. Waste Management and Research, 2000. 18(6): p. 545-556.

[19] Ando, A.W. and A.Y. Gosselin, Recycling in multifamily dwellings: does convenience matter? Economic inquiry, 2005. 43(2): p. 426-438.

[20] Oskamp, S., et al., Factors influencing household recycling behaviour. Environment and behaviour, 1991. 23(4): p. 494-519.

[21] Barr, S., N.J. Ford, and A.W. Gilg, Attitudes towards recycling household waste in Exeter, Devon: quantitative and qualitative approaches. Local Environment, 2003. 8(4): p. 407-421.

[22] Martin, M., I.D. Williams, and M. Clark, Social, cultural and structural influences on household waste recycling: A case study. Resources, conservation and recycling, 2006. 48(4): p. 357-395.

[23] Barr, S., Factors influencing environmental attitudes and behaviours: A UK case study of household waste management. Environment and behaviour, 2007. 39(4): p. 435-473.

[24] Pocock, R., et al., Barriers to recycling at home. Banbury, UK: Waste and Resources Action Programme, 2008.

[25] Schultz, P.W., S. Oskamp, and T. Mainieri, Who recycles and when? A review of personal and situational factors. Journal of environmental psychology, 1995. 15(2): p. 105-121.

[26] Perry, G. and I. Williams, The participation of ethnic minorities in kerbside recycling: A case study. Resources, Conservation and Recycling, 2007. 49(3): p. 308-323.

[27] Hage, O., P. Söderholm, and C. Berglund, Norms and economic motivation in household recycling: Empirical evidence from Sweden. Resources, Conservation and Recycling, 2009. 53(3): p. 155165.

[28] RRF, Household Waste Behaviour in London. 2001: Skipton, UK.

[29] Do Valle, P.O., et al., Behavioural determinants of household recycling participation: the Portuguese case. Environment and behaviour, 2004. 36(4): p. 505-540.

[30] Hornik, J., et al., Determinants of recycling behaviour: A synthesis of research results. The Journal of Socio-Economics, 1995. 24(1): p. 105- 127.

[31] Mahapatra, K., Resource Efficient Cities Implementing Advanced Smart City Solutions - READY. 2020.

[32] F. Sartipi, "Automatic sorting of recycled aggregate using image processing and object detection," Journal of Construction Materials, vol. 1, pp. 3-3, 2020, doi: https://doi.org/10.36756/JCM.v1.2.1. 
[33] T. Boulos, F. Sartipi, and K. Khoshaba, "Bibliometric analysis on the status quo of robotics in construction," Journal of Construction Materials, vol. 1, pp. 2-3, 2020.

[34] F. Sartipi, "A brief critical view on the carbon-conditioning of recycled aggregate using pressure chamber," Journal of Construction Materials, vol. 2, pp. 1-4, 2020, doi: https://doi.org/10.36756/JCM.v2.1.4.

[35] F. Sartipi, "Diffusion of Innovation Theory in the Realm of Environmental Construction," Journal of Construction Materials, vol. 1, pp. 4-2, 2020, doi: https://doi.org/10.36756/JCM.v1.3.2.

[36] F. Sartipi, "Dynamic data processing for building energy consumption," Journal of Construction Materials, vol. 2, no. 2021, pp. 2-4, 2020, doi: https://doi.org/10.36756/JCM.v2.2.4.

[37] F. Sartipi, "Negative interest rate: Way to tackle inflationary housing prices," Journal of Construction Materials, vol. 2, pp. 4-1, 2021, doi: https://doi.org/10.36756/JCM.v2.4.1.

[38] F. Sartipi, "Publicizing construction firms by cryptocurrency," Journal of Construction Materials, vol. 2, pp. 3-1, 2021, doi: https://doi.org/10.36756/JCM.v2.3.1. 